\title{
AS INFLUÊNCIAS DO NEOLIBERALISMO NA EDUCAÇÃO BRASILEIRA: ALGUMAS CONSIDERAÇÕES.
}

Daniela Basso Mestre em Educação pelo PPGE/DE/ UFSCar. Pesquisadora do Grupo de Estudos e Pesquisas sobre Educação do Campo- GEPEC/ UFSCar/HISTEDBR. jdbassoufscar@hotmail.com

Luiz Bezerra Neto Doutor em Educação pela UNICAM Professor Adjunto do Departamento de Educação da UFSCar. Coordenador do Grupo de Estudos e Pesquisas sobre Educação do CampoGEPEC/UFSCar/HISTEDBR lbezerra@ufscar.br

RESUMO: Neste trabalho nos dedicaremos à compreensão da influência do neoliberalismo na economia e na educação brasileira, que se tornou preponderante a partir dos anos 1990 e que tem aprofundado as desigualdades sociais e diminuído ainda mais os investimentos em bens sociais como a educação. Desta maneira, pretendemos compreender de que forma as políticas neoliberais tem se apresentado no Brasil e quais suas implicações, principalmente na educação do país.

Palavras- chave: Neoliberalismo, Banco Mundial, Economia e Educação.

ABSTRACT: In this paper we devote to understanding the influence of neoliberalism in economics and education in Brazil, which became predominant from the 1990s and that has deepened social inequalities and further decreased investment in social goods such as education. In this way, we aim to understand how neoliberal policies has performed in Brazil and what its implications, especially in the country's education.

Key- words: Neoliberalism, the World Bank, Economics and Education. 


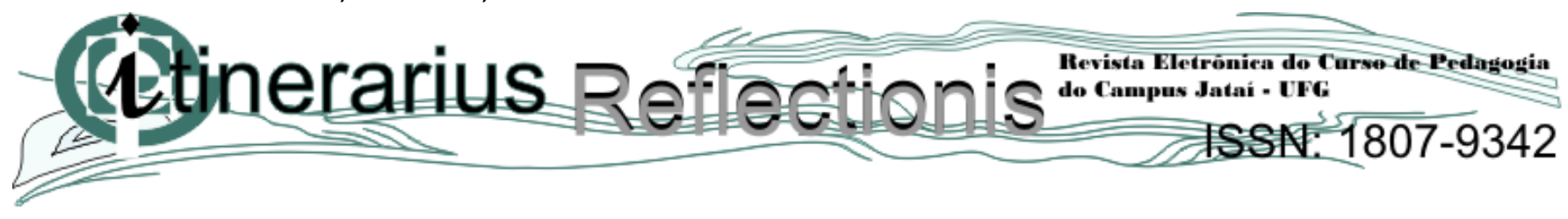

\section{AS INFLUÊNCIAS DO NEOLIBERALISMO NA EDUCAÇÃO BRASILEIRA: ALGUMAS CONSIDERAÇÕES.}

Neste trabalho nos dedicaremos à compreensão da influência do neoliberalismo na economia e na educação brasileira, que se tornou preponderante a partir dos anos 1990 e que tem aprofundado as desigualdades sociais e diminuído ainda mais os investimentos em bens sociais como a educação. Estes escritos são parte da dissertação de mestrado intitulada "As escolas no campo e as salas multisseriadas no Estado de São Paulo: um estudo sobre as condições da educação escolar" defendida no Programa de Pós-Graduação em Educação da Universidade Federal de São Carlos, trabalho que nos fez perceber que o neoliberalismo não está na causa das dificuldades educacionais enfrentadas no Brasil, mas contribui como um agravante destas dificuldades.

Muito se discutiu no final da década de 1990 e início da década de 2000 sobre o neoliberalismo, porém esta discussão ainda se faz necessária, uma vez que, as políticas neoliberais são preponderantes no mundo todo. Desta maneira, pretendemos, a partir de revisão bibliográfica, compreender de que forma as políticas neoliberais tem se apresentado no Brasil e quais suas implicações, principalmente na educação.

De acordo com Perry Anderson,

o neoliberalismo nasceu logo depois da II Guerra Mundial, na região da Europa e da América do Norte onde imperava o capitalismo. Foi uma reação teórica e política veemente contra o Estado intervencionista e de bem-estar. Seu texto de origem é O caminho da Servidão, de Friedrich Hayek, escrito já em 1944. Trata-se de um ataque apaixonado contra qualquer limitação dos mecanismos de mercado por parte do Estado, denunciadas como uma ameaça letal à liberdade, não somente econômica, mas também política (ANDERSON, 1996, p. 9).

Embora tenha sido pensado já na década de 1940, Göran Therborn (1996, p. 139) afirma que o neoliberalismo enquanto conjunto de receitas e programas políticos começou a ser proposto nos anos 1970. Ou seja, o neoliberalismo foi gestado ainda nos anos 40, mas começou a ser colocado em prática na década de 1970, período em que a crise do petróleo desencadeou uma grande recessão capitalista. O capitalismo, modelo econômico que impera na contemporaneidade, passou por seus anos de ouro no mundo entre as décadas de 1950 e 1960, uma vez que nunca havia crescido de modo tão rápido, assim, naquele período, não existiam motivos para preocupações com os avisos dos neoliberais quanto aos perigos guardados por uma regulação de mercado feita pelo Estado (ANDERSON, 1996, p.10).

A grande crise do petróleo, que o capitalismo enfrentou após 1973, fez com que o mundo capitalista mergulhasse em uma grande e duradoura recessão, que veio acompanhada de baixas taxas de crescimento e altos índices de inflação, tudo isto fez com que as ideias neoliberais ganhassem terreno. Hayek e seus companheiros defendiam que as causas da crise estavam no movimento operário, que com suas reivindicações por melhores salários e pressão para que o Estado gastasse mais com o bem estar social, destruiu os níveis necessários de lucros das empresas 


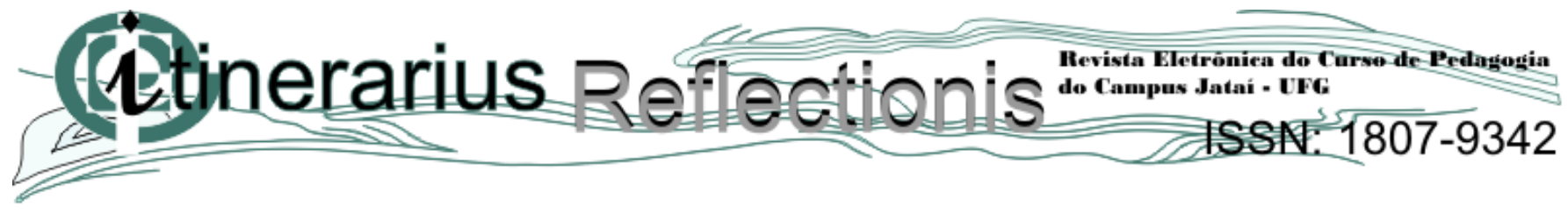

e com isso fez disparar a inflação, que logo desencadearia uma crise generalizada. Para conter esta crise, de acordo com os defensores do neoliberalismo, seria necessário manter um Estado forte capaz de refrear o movimento dos sindicatos e controlar o dinheiro por meio do enxugamento dos gastos sociais e intervenções econômicas (ANDERSON, 1996, p. 10).

Desta maneira, em busca da estabilidade monetária, qualquer governo alinhado ao neoliberalismo deveria reduzir os gastos com o bem estar social, o que aqui podemos compreender como gastos com a saúde, educação e fundos de pensão, e restaurar a taxa "natural" de desemprego, ou seja, criar uma reserva de mão de obra para derrubar o poder dos sindicatos, além, é claro, de reduções de impostos sobre os maiores rendimentos e rendas. Ou seja, tudo isso faria com que uma nova e "saudável desigualdade" colocasse novamente a roda do capitalismo e do crescimento dos lucros para girar (ANDERSON, 1996, p. 11).

No Brasil, que é uma sociedade capitalista, teve-se a ilusão inicial de que o neoliberalismo não seria letal, entretanto, os dirigentes do período ditatorial eram todos liberais, porém, respaldados por um autoritarismo típico dos militares. Assim, com a ditadura civil-militar (19641985) iniciou-se também o processo de depredação do Estado brasileiro, que atravessou o mandato de José Sarney (1985-1990) e a eleição de Fernando Collor de Mello (1989), esta depredação desencadeou o desespero popular que via os desperdícios do Estado como bode expiatório da má distribuição de renda, da precariedade da saúde, educação e dos demais serviços sociais (OLIVEIRA, 1996, p. 24).

O desespero popular fez com que, na década de 1980, em meio a um desânimo econômico, a sociedade civil mostrasse uma admirável vitalidade e capacidade de revidar ao ataque neoliberal, organizando-se. O processo de impeachment de Fernando Collor de Mello demonstrou que em certos setores e lugares a organização social estava reagindo à desorganização e depredação do Estado, e este processo, conseguiu responder e dificultar o avanço neoliberal pretendido por Collor, contudo, a hiperinflação administrada em doses homeopáticas na primeira parte do governo Itamar Franco (1992-1994), fez com que o Brasil voltasse a ser um terreno fértil para as investidas neoliberais (OLIVEIRA, 1996, p. 25).

Em um primeiro momento, o povo brasileiro não viu o neoliberalismo como ameaça, até mesmo porque estava sob a égide do governo militar que tinha o Estado como sua maior arma de controle social, contudo, o autoritarismo militar mascarava os traços liberais dos governantes. No governo de Fernando Collor de Mello (1990-1992) já se viam os reflexos do neoliberalismo pelas más condições de serviços públicos como a saúde, educação e a desigualdade na distribuição de renda. Diante desta situação, a população viu em Collor e em seus desperdícios orçamentários a causa das mazelas sociais, e, sua derrubada foi a maneira encontrada para demonstrar o descontentamento popular e a busca por mudanças. Porém, este ato popular não foi suficiente para conter o avanço do neoliberalismo, que já havia tomado conta da América Latina.

O que se tem visto no mundo desde a década de 1970 e no Brasil, sobretudo após a década de 1990, é o domínio do poder do mercado anônimo em detrimento do poder dos trabalhadores e empresas. Após a II Guerra (1939-1945), os mercados mundiais se abriram e o comércio mundial passou a crescer mais do que a própria produção, até mesmo as grandes empresas passaram a ser dependentes dos mercados (THERBORN, 1996, p. 141). 


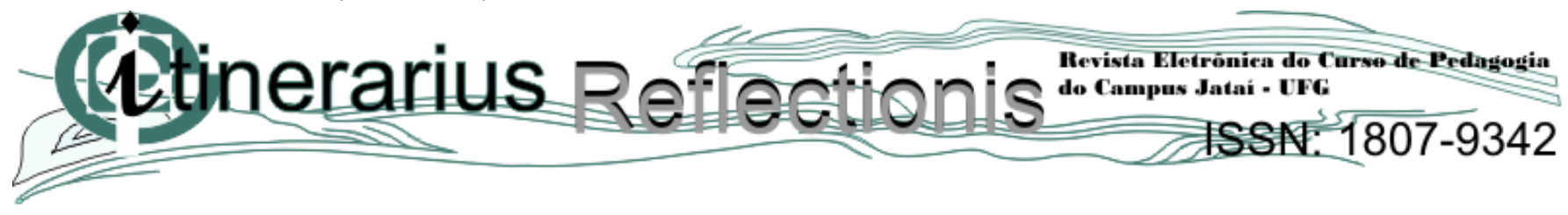

O neoliberalismo gerou a abertura de mercados e certo crescimento econômico, porém, o custo deste crescimento foi bastante alto. Ele foi implantado, tendo como prioridade conter a inflação dos anos 1970/ 1980, tarefa que foi alcançada, mas, levou à derrocada dos movimentos sindicais, dada a diminuição do número de greves na Europa, a partir dos anos 1980, e a contenção dos salários por meio do aumento das taxas de desemprego, tido como mecanismo natural e necessário nas economias de mercado lucrativas. Todas estas medidas foram aplicadas em busca da reanimação do capitalismo avançado e altas taxas de crescimento estável (ANDERSON, 1996, p. 14). Isto na Europa, pois, naquele período, o Brasil vivenciou várias greves e a criação de movimentos sindicais como a CUT- Central Única dos Trabalhadores.

A desigualdade social é um dos reflexos negativos do neoliberalismo e em países como a Argentina, o México e o Brasil ela é fruto do modelo de integração empreendido, que propõe um retorno ao antigo molde de exportação de recursos naturais, quebrando o aparato industrial já desenvolvido por estes países e gerando desemprego (SALAMA, 1996a, p. 52). O que nos leva a refletir sobre a maneira como o neoliberalismo age nos países latino americanos, políticas de integração comercial baseadas na exportação de riquezas naturais colaboram para a manutenção do grande latifúndio, que sabidamente emprega cada vez menos pessoas devido à mecanização das lavouras e prejudica diretamente o pequeno produtor rural, que não possui capital, tampouco recebe investimentos que permitam que sua produção concorra no mercado.

Temos aqui uma reação em cadeia, um mercado concorrencial que impulsiona a América Latina a ser fornecedora de produtos naturais, com isto há um enfraquecimento da indústria e diminuição na oferta de empregos neste ramo, tudo isto culmina com um maior número de pessoas sem emprego e necessitadas do auxílio do Estado, que devido aos moldes neoliberais não tem as políticas públicas como prioridade, e acaba deixando as massas populares em situação de extrema pobreza.

Mônica Castagna Molina (2012, p. 588) diz que as políticas públicas,

traduzem as formas de agir do Estado, mediante programas que objetivam dar materialidade aos direitos constitucionais. Entre os direitos constitucionais que se materializam por meio das políticas públicas, estão principalmente os direitos sociais, definidos no artigo $6^{\circ}$ da Constituição Federal brasileira de 1988: educação, saúde, trabalho, moradia, lazer, segurança, previdência social, proteção à maternidade e à infância e assistência aos desamparados. Pelo fato de as políticas públicas serem formas de atuação do Estado para garantir os direitos sociais, elas também são denominadas, muitas vezes, políticas sociais.

Parece-nos claro que o Estado neoliberal não tem as políticas públicas como prioridade, uma vez que, os resultados da contradição atual do capitalismo, mais ideológica que econômica, traduzse na destruição social gerada pelo poder de mercado.

Vemos em todos os países, não somente na América Latina, tendências a um desemprego de massas de caráter permanente, uma produção da pobreza e, também, o surgimento de um alto grau de desesperança e de violência, inclusive nos países escandinavos. Esta tendência autodestrutiva da competição atual no capitalismo, geradora de mecanismos cada vez mais intensos de exclusão social de uma grande parte da população, é um aspecto central desta contradição sociológica. 


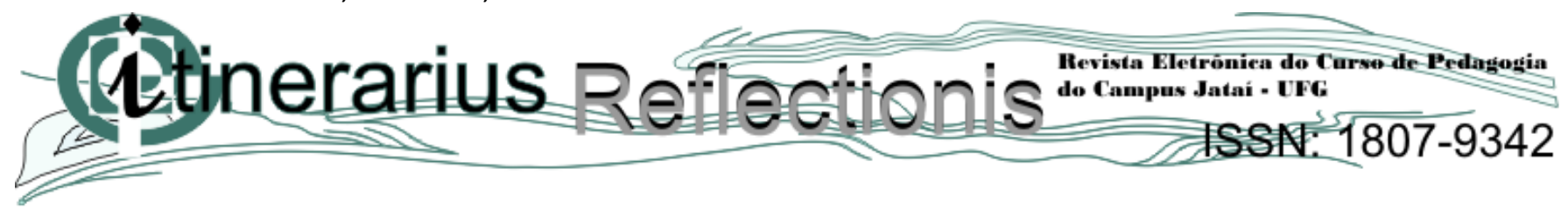

No entanto, o problema não se esgota aí. As tendências destrutivas do capitalismo se enfrentam também com populações historicamente mais capacitadas. Tanto em nível mundial como local, estas tendências tropeçam em classes populares e classes médias mais instruídas, o que constituí um dado sumamente importante (THERBORN, 1996, p. 47).

Novamente nos deparamos com as contradições sociais geradas pelo neoliberalismo, a pauperização, aumento da violência e exclusão social. Contudo, é preciso termos certos cuidados com o termo exclusão social, visto que os indivíduos não são retirados da sociedade e de suas influências, na verdade, quando falamos em exclusão social, estamos nos referindo à falta de acesso aos bens sociais, ou seja, educação, saúde, seguridade social, entre outros.

O acesso aos conhecimentos está no centro de uma contradição que permeia o processo de reestruturação social que as sociedades capitalistas vêm enfrentando desde os anos 1990. Em um pólo temos a tendência à fragmentação e diversificação social, que coloca em discussão a questão das especificidades como gênero, raça, crenças, entre tantos, fenômeno tratado por Perry Anderson como a construção de uma nova estratificação das classes populares, no outro pólo temos uma ação em busca de maior capacitação das classes populares, visto que nas sociedades capitalistas desenvolvidas, a tendência predominante é buscar uma melhor qualificação da força de trabalho (THERBORN, 1996, p. 48).

Atílio Borón afirma que os países latino-americanos sob o jugo do neoliberalismo, colhem e ainda colherão frutos das políticas econômicas implantadas na década de 1980, que gerou um tipo de sociedade heterogênea e desequilibrada que convive com extremos de pobreza e marginalidade social e outros de riqueza e ostentação. Neste contexto, nos deparamos com uma mão de obra pauperizada, faminta, cada vez menos escolarizada, carente de atenção social, sanitária e habitacional, mão de obra esta que certamente não contribuirá para a inserção dos países latino americanos na economia internacional (BORÓN, 1996a, p. 84).

Em contrapartida, as sociedades desenvolvidas realizaram um movimento inverso, investindo no capital humano, o que gerou a redução da pobreza e equidade social (BORÓN, 1996a, p. 84). Podemos então caminhar em nossas análises ao perceber que o não investimento na educação das massas populares, que vendem sua força de trabalho, acaba sendo um processo contraditório nas sociedades, sobretudo a partir dos investimentos realizados por empresas e estados, sob orientações de políticas neoliberais pois, a desqualificação da mão de obra impossibilita a inserção dos países em ramos mais especializados do mercado.

No Brasil, sobretudo após a promulgação da Lei de Diretrizes e Bases da Educação Nacional - LDB, em 1996, houve uma expansão no acesso à educação escolar nunca antes vista em outro momento histórico. Ocorre que tanto a LDB quanto a Constituição Federal e o Estatuto da Criança e do Adolescente primaram pela expansão da escolarização, não garantindo condições mínimas de qualidade, ou seja, trata-se de uma educação voltada apenas para a instrumentalização do trabalhador e não para garantir que ele se aproprie dos conhecimentos historicamente produzidos pela humanidade e seja formado integralmente.

Uma comprovação disto é o projeto de lei 8.035/2010 que tramita no Congresso Nacional que visa implementar o Plano Nacional de Educação que deveria vigorar de 2011 a 2020. Este 


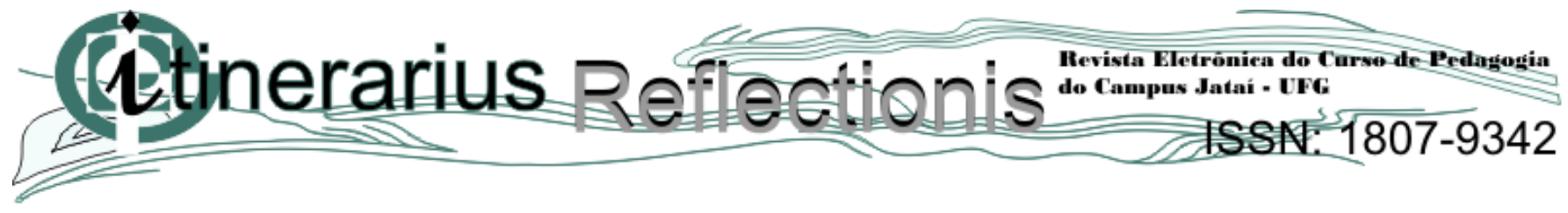

plano privilegia a Educação Básica, portanto, a Educação Infantil, o Ensino Fundamental e Ensino Médio, uma vez que, afirma ser a missão central do país, no período de vigor do plano, a redução da desigualdade educacional. Com isto, promete-se assegurar a escolaridade mínima de 12 anos para as populações do campo, das regiões de menor escolaridade e para os $25 \%$ mais pobres do país, aumentando assim a escolaridade média dos brasileiros entre 18 e 24 anos (BRASIL, 2011, p. 68).

Juntamente a esta meta estão previstos a elevação da taxa de alfabetização das pessoas com mais de 15 anos, a erradicação do analfabetismo até 2015 e redução da taxa de analfabetismo funcional (BRASIL, 2011, p. 69), ou seja, a diminuição do número de pessoas que são consideradas oficialmente alfabetizadas, mas não dominam plenamente a leitura e a escrita. Desta maneira, percebemos que a prioridade da educação pública brasileira é retirar as pessoas mais pobres da condição de analfabetismo, permitindo assim que sejam integradas ao mercado de trabalho, para a realização de atividades que exigem baixa qualificação.

Tanto as leis supra citadas, quanto o Plano Nacional de Educação estão pautados nos quatro pilares da Educação elencados no relatório para a UNESCO da Comissão Internacional sobre Educação para o século XXI "Educação um tesouro a descobrir" organizado e coescrito por Jacques Delors, no relatório a educação no presente século é vista da seguinte maneira:

Dado que oferecerá meios, nunca antes disponíveis, para a circulação e armazenamento de informações para a comunicação, o próximo século submeterá a educação a uma dura obrigação que pode parecer, à primeira vista, quase contraditória. A educação deve transmitir, de fato, de forma maciça e eficaz, cada vez mais saberes e saber- fazer evolutivos, adaptados à civilização cognitiva, pois são as bases das competências do futuro. Simultaneamente, compete-lhe encontrar e assinalar as referências que impeçam as pessoas de ficar submergidas nas ondas de informações, mais ou menos efêmeras, que invadem os espaços públicos e privados e as levam a orientar-se para os projetos de desenvolvimento individuais e coletivos. À educação cabe fornecer, de algum modo, os mapas de um mundo complexo e constantemente agitado e, ao mesmo tempo, a bússola que permita navegar através dele. Nesta visão prospectiva, uma resposta puramente quantitativa à necessidade insaciável de educação- uma bagagem escolar cada vez mais pesadajá não é possível nem mesmo adequada (DELORS, 1998, p. 89).

Percebemos aqui a valorização do "saber-fazer", do saber navegar nas ondas de informação, ou seja, sob esta concepção a educação já não mais deve oferecer uma "bagagem pesada" de conhecimentos, mas permitir que os indivíduos saibam apreender aquilo que lhes é útil em meio a tempestade de informações que a mídia e os meios de comunicação em geral lhe impõem cotidianamente.

Assim, as quatro aprendizagens consideradas fundamentais para o século XXI se organizam em quatro pilares, são eles:

Aprender a conhecer, isto é adquirir os instrumentos de compreensão; aprender a fazer, para poder agir sobre o meio envolvente; aprender a viver juntos, a fim de participar e cooperar com os outros em todas as atividades humanas; finalmente aprender a ser, via essencial que integra as três precedentes. É claro que estas quatro vias do saber constituem apenas uma, dado que existem entre elas múltiplos 


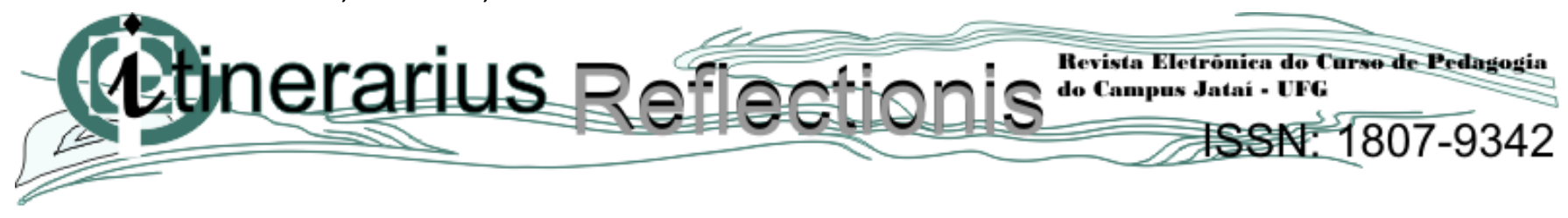

pontos de contato, de relacionamento e de permuta. Mas, em regra geral, o ensino formal orienta-se, essencialmente, se não exclusivamente, para o aprender $a$ conhecer e, em menor escala, para o aprender a fazer. (DELORS, 1998, p.90).

Estes pilares explicam, e justificam de certa forma, o investimento mínimo em educação no Brasil, dado que, se o grande norte da educação é o aprender a conhecer, a mídia e os meios de comunicação dariam conta de oferecer as informações necessárias para que o indivíduo possa aprender a viver junto e ser o trabalhador que o século XXI requisita. Caberia então a escola básica a tarefa mínima de ensinar o aluno a ler, escrever e dominar as quatro operações matemáticas para que ele se aproprie dos infinitos conhecimentos informais.

Trata-se a nosso ver da desvalorização dos conhecimentos historicamente construídos, da banalização da necessidade de uma formação integral dos indivíduos, o que nos leva a um questionamento, esta educação esvaziada de conteúdos, "amena" é oferecida a todos os indivíduos da sociedade, ou a elite e seus filhos está tendo acesso a outra educação, mais erudita, formal, que lhes permite alcançar altos graus de formação acadêmica e profissional, para que comandem a grande massa popular mal formada?

A expansão educacional sob a perspectiva do neoliberalismo tem disseminado a formação mínima, que instrumentaliza a maior parte da classe trabalhadora, e especializa parte dela para suprir as necessidades produtivas, e paralelamente a esta realidade existe a educação da e para a elite que, abrigada no sistema privado de ensino, não abre mão dos conteúdos e das "cargas pesadas" de conhecimento.

Vemos que o acesso aos conhecimentos está diretamente relacionado à classe social a qual o indivíduo pertence, à utilidade que eles terão em sua vida laboral. Atílio Borón (1996b, p. 100) alerta que estes contrassensos sociais não deixam as nações perceberem que nas condições atuais do mercado internacional, economias caracterizadas por divisões e descontinuidades estruturais, delimitadas por desigualdades sociais e baixos níveis de saúde e educação da mão de obra estão fadadas a serem eternas perdedoras em um mercado cada vez mais competitivo.

Duas das ferramentas utilizadas pelos defensores do neoliberalismo para disseminar seus princípios são o Banco Mundial-BM e o Fundo Monetário Internacional-FMI. O BM e o FMI, instituições fundadas respectivamente em 1945 e 1946, são frutos das deliberações da Conferência de Bretton Woods, que ocorreu na cidade homônima nos Estados Unidos, no ano de 1944, com a participação de quarenta e quatro países, inclusive a União Soviética. Esta foi "uma conferência monetária e financeira para estabelecer as orientações do 'liberalismo global' que haveria de prevalecer na emergente ordem mundial do pós-guerra” (BORÓN, 1996a, p. 91).

As temáticas predominantes na conferência de Bretton Woods giraram em torno da elaboração das novas regras que regeriam o funcionamento da reconstituída economia mundial e a concepção das instituições que zelariam por sua validade. As discussões partiam do pressuposto de que o protecionismo comercial era o grande responsável pelas tragédias econômicas que ocorreram nas três décadas posteriores ao início da Primeira Guerra Mundial.

As deliberações da conferência caminharam rumo à criação de mecanismos que garantiriam o livre comércio, o fim de qualquer tipo de protecionismo econômico, a ajuda a países vitimados 


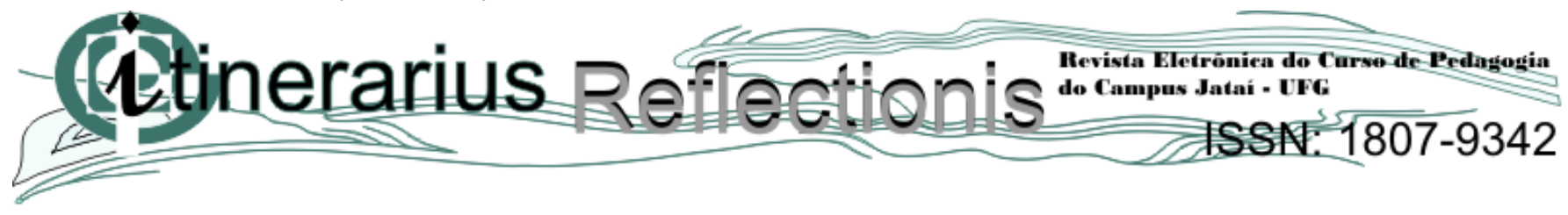

pela queda de exportações, déficits orçamentários, entre outras dificuldades econômicas e a reconstrução da economia de países devastados pelas guerras (BORÓN, 1996a, p. 91).

Aqui visualizamos os princípios liberais que deram origem ao Banco Mundial, a busca pelo livre comércio e a chamada libertação do protecionismo estatal e percebemos que em sua constituição, o Banco estava voltado para o auxílio a problemas econômicos imediatos e a reestruturação de economias devastadas pelas guerras. Com sua gênese enraizada em princípios notadamente liberais, fica-nos claro o motivo pelo qual o FMI e o BM são a via costumeira de disseminação e dominação das políticas neoliberais, visto que ao analisarmos sua atuação, veremos que estas instituições ganharam força após os anos 1980 em países periféricos tomados pela crise e o endividamento externo.

Atualmente, o BM guarda pouca semelhança em relação à organização criada em 1945. Ao longo de quase setenta anos de atividade, o Banco passou por inúmeras transformações tanto na ênfase de suas políticas, distribuição setorial dos recursos e importância política dos países membros, que em 2007 já totalizavam 176, dentre eles China e países do Leste Europeu. Poucos anos após a Conferência de Bretton Woods, a Guerra Fria colocou no centro das preocupações a assistência econômica, política e militar aos países do Terceiro Mundo, esperava-se com isto que os países independentes se unissem à aliança não-comunista, assim, o BM se envolveu cada vez mais no processo de estabilização e expansão do sistema capitalista mundial por meio da liberação de empréstimos após os anos 1950 (SOARES, 2007, p. 15).

Dos anos 1950 em diante o BM adquiriu a característica de agência financiadora dos países em desenvolvimento. Em 1968, inicia-se uma nova etapa na instituição, marcada pela gestão Robert MacNamara, antes deste período tinha-se a ideia de que o desenvolvimento econômico por si só levaria ao desaparecimento da pobreza nos países em desenvolvimento, contudo, mesmo após duas décadas de crescimento econômico a pobreza perdurava, assim como o distanciamento entre as nações ricas e pobres. Desta forma, a administração de MacNamara marcou o surgimento de uma preocupação pontual com a pobreza e promoveu uma redistribuição setorial dos empréstimos, que antes se concentravam em investimentos infra-estruturais e passaram a contemplar mais a agricultura, indústria e setores sociais (SOARES, 2007, p. 18).

Esta redistribuição pretendia alcançar os países capitalistas devedores, então, a instituição financeira lapidou sua política econômica e estratégias para abranger e modificar a economia dos países devedores, tornando-se assim, a única instituição que possuía ferramentas para a promoção da redução da pobreza, analfabetismo e a possibilidade de implantar políticas econômicas competitivas e lucrativas. As relações dos países com o BM geram uma série de influências que começam com recomendações e terminam em exigências que devem ser cumpridas para a obtenção de novos empréstimos (SILVA, 2003, p. 286).

Maria Clara Couto Soares (2007, p. 17) avalia negativamente a atuação do Banco Mundial, visto que, a instituição tem financiado um desenvolvimento econômico desigual e socialmente cruel, que aumentou a pobreza global, a concentração de renda, a exclusão ao acesso aos bens sociais e degradação do meio ambiente. O Brasil não escapa a esta situação, durante o período do avanço da economia, que durou até fins dos anos 1970, o BM promoveu a "modernização" do campo e financiou uma série de grandes projetos industriais e infraestruturais no país que 


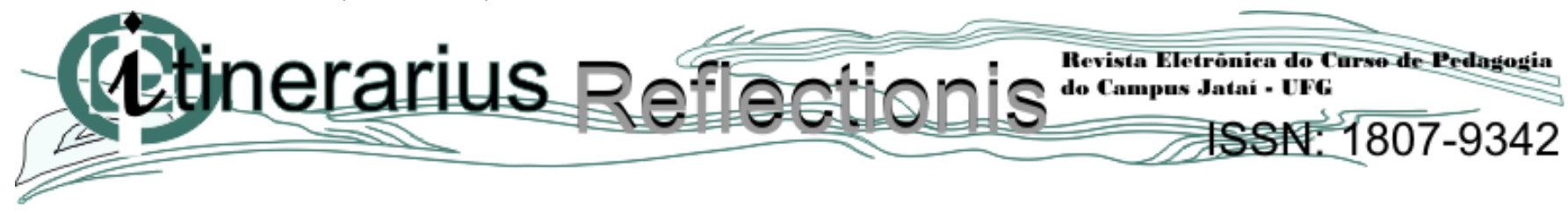

colaboraram para a ascensão de um modelo desenvolvimentista concentrador de renda e despreocupado com os prejuízos causados ao meio ambiente.

A partir dos anos 1970, o BM que anteriormente concentrava seus investimentos em infraestrutura e energia, passa a se dedicar a questões sociais, investindo no incremento da produção, sobretudo a agrícola, como uma medida de contenção do avanço da pobreza. Assim, a educação, que até então não era privilegiada, passa a ter acesso aos créditos da agência. Dos anos 1970 até 1990, o BM elaborou políticas educacionais que direcionaram a distribuição de créditos para este setor, dois traços nestas políticas são marcantes, o primeiro deles é a busca da integração dos projetos educacionais a projetos setoriais como, por exemplo, o de desenvolvimento rural. O segundo é atribuição de caráter compensatório à educação, entendida como ferramenta para diminuição da condição de pobreza nos países do Terceiro Mundo, principalmente em períodos de ajustamento econômico (FONSECA, 2007, p. 231).

O BM tem declarado sua preocupação social com os países de terceiro mundo, hoje denominados em desenvolvimento, esta preocupação recai sobre a qualificação para o trabalho e não sobre a educação conceituada por Dermeval Saviani, educação entendida como um processo que se caracteriza por meio de uma atividade mediadora no seio da prática social global (SAVIANI, 2000b, p. 131). Ou seja, é a educação que permite ao homem se apropriar das práticas sociais, que lhe caracteriza enquanto humano, é através dela que se tem acesso aos conhecimentos historicamente produzidos pela humanidade. Portanto, consideramos que, a educação não pode ser reduzida à mera auxiliar no processo de desenvolvimento econômico, tampouco ser considerada medida compensatória para alívio da pobreza como pregam as políticas educacionais do Banco Mundial.

Este reducionismo da educação empreendido pelo BM nos parece nítido, dada a ênfase de suas políticas, desde os anos 1970, aos quatro primeiros anos do Ensino Fundamental. A instituição considerava, naquele período, que os anos iniciais do Ensino Fundamental seriam suficientes para garantir às massas um ensino mínimo e de baixo custo, que viabilizasse a execução das políticas de estabilização econômica que foram intensificadas na década de 1980, assim, a educação aparece como uma medida compensatória para o alívio da pobreza e um fator de contenção do crescimento demográfico e aumento da produtividade entre as populações mais pobres (FONSECA, 2007, p. 232).

A política do Banco para a educação primária tem sido fundamentada por estudos populacionais realizados diretamente pelo BIRD ("Banco Mundial") ou sob seus auspícios. Os resultados atribuem ao nível primário maior capacidade de preparação da população feminina para a aceitação das políticas de planejamento familiar e também para o estímulo à intensificação de sua participação na vida produtiva, especialmente no setor agrícola (FONSECA, 2007, p. 233).

Novamente vemos que os investimentos do Banco Mundial na educação visam fins econômicos visto que, o mínimo de ensino que considera necessário oferecer deve capacitar os indivíduos para produzirem mais e terem menos filhos, reduzindo assim a necessidade por alimentos e consequentemente os índices de fome e pobreza extremos. A educação empreendida pelo BM, dadas suas premissas neoliberais, serve diretamente aos interesses do capital, uma vez que, busca preparar mulheres para a aceitação, pouco refletida, das políticas de contenção da 


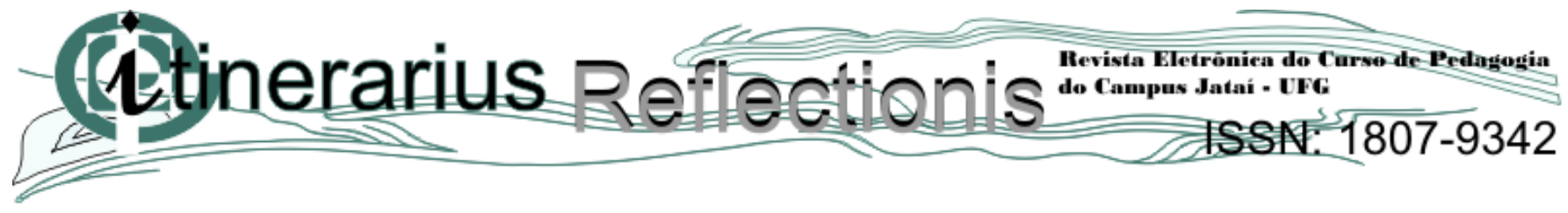

natalidade, bem como estimular sua inserção no mercado de trabalho. Ou seja, é uma educação para o conformismo e concordância com a ordem econômica capitalista, que constantemente busca a reposição da mão de obra e explora aqueles que não detêm os meios de produção.

Soares (2007, p. 30) confirma esta situação ao nos dizer que o Banco vem dando ênfase à educação, não somente como ferramenta para a redução da pobreza, mas como peça fundamental para a formação de "capital humano", ou seja, mão de obra, coerente com as exigências do novo padrão de acumulação. Contudo, a própria instituição admite que suas medidas para contenção da pobreza tem sido pouco eficazes. Esta constatação nos faz perceber que a educação tem sido utilizada como uma das ferramentas do Banco para a redução da pobreza. Se assim é, a instituição não deveria pensar sobre as políticas educacionais empreendidas, já que as considera ineficientes?

No Brasil este ideário é traduzido na influência dos diretores, técnicos e conselheiros do Banco Mundial nas decisões educacionais e nas pressões sobre o governo, que estão embasadas num discurso que traz as seguintes considerações: as estruturas capitalistas internas estão distantes do atual modelo de modernidade, daí a necessidade de ajuda e cooperação técnica externas; os países subdesenvolvidos são marcados pelo monopólio oligárquico e conservador na estrutura de poder, o que dificulta a aceitação de uma nova mentalidade, neoliberal no caso; há dificuldade do governo federal em planejar a educação, tendo em vista que ela é a responsável pela qualificação da mão de obra; o próprio empresariado industrial do país vê a presença das multinacionais e o mercado de ensino como possibilidades de aumento de lucros; a abertura de mercados para as multinacionais e os bancos estrangeiros se tornou necessária e a globalização inquestionável, um exemplo desta pressão pode ser a exigência de licitações para compra de materiais didáticos de outros países; aconselhamento quanto à mudança dos rumos dos investimentos na educação, propondo a redução dos custos e induzindo o pensamento de que o Ensino Fundamental seja prioridade nos investimentos e que os demais níveis educacionais podem ser ofertados pela iniciativa privada; pressão aos ministros e técnicos para que suas decisões favoreçam a entrada de capital estrangeiro no país, através de empresas de construção civil, transporte, telefonia, alimentos e equipamentos; indução de ações setoriais e isoladas que combatam a má qualidade do ensino e reorganizem o currículo, um exemplo disto são os Parâmetros Curriculares Nacionais e o FUNDESCOLA; tratamento da educação como serviço público que pode ser transferido para as empresas privadas e a indução de atitudes que priorizem a cultura empresarial nas escolas, ou seja, a otimização da relação eficaz entre os recursos públicos e a produtividade do sistema escolar (SILVA, 2003, p. 287).

Analisando o discurso do Banco Mundial percebemos quanto à educação, a sociedade civil e o Governo Federal brasileiro são influenciados por ele. Comecemos pela crítica ao modelo capitalista empreendido no país, considerado atrasado em relação aos países desenvolvidos, e que justificaria a influência de agências externas na economia nacional.

Vemos claramente nas considerações do BM, a preocupação econômica por trás dos objetivos educacionais, na crítica feita ao governo por ter dificuldades em arquitetar a educação em função da formação de mão de obra. Contudo, se o Brasil segue grande parte das diretrizes do Banco e as incorpora em suas ações e legislação educacional, e essas diretrizes são em favor de uma educação para a qualificação da mão de obra, esta crítica se tornaria incoerente. 


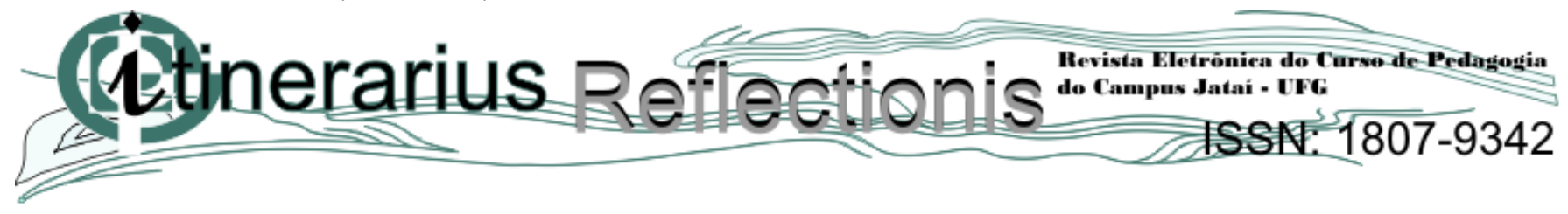

Outro dado que pode ser percebido é a aceitação do empresariado industrial brasileiro quanto à entrada das multinacionais no país e, a não contestação ao processo de globalização e mercantilização da educação, estes pontos são reflexos claros das proposições do neoliberalismo visto que, como já afirmamos anteriormente, uma das premissas neoliberais é abertura dos mercados ao capital externo, que é traduzida no processo de globalização, e a busca pelo aumento de lucros.

Neste contexto, um dos reflexos mais marcantes das proposições do Banco na educação brasileira é a concentração dos investimentos no Ensino Fundamental e a busca por redução dos custos educacionais (SILVA, 2003, p. 287). Vemos que se comparado às décadas 1970-1980, em que o discurso do BM pregava que apenas os anos iniciais do Ensino Fundamental eram suficientes houve um avanço contudo, as premissas econômicas ainda sobrepujam as preocupações com a educação na concessão de créditos. Certamente, a diminuição dos custos é a imposição que mais gera prejuízos na educação brasileira, pois, reduzir custos implica manter baixos salários e níveis de formação docente, diminuir os investimentos em infraestrutura escolar e material didático, o que resulta na diminuição da qualidade da educação.

O alinhamento das leis educacionais brasileiras com as políticas neoliberais também se evidencia na obrigatoriedade e gratuidade do Ensino Fundamental para aqueles que não frequentaram na idade apropriada, esta medida compensatória, busca em seu cerne, integrar um maior número de indivíduos ao mercado de trabalho, visto que ao se escolarizarem, passam a atender aos requisitos exigidos pelo capital. Mostrando também que o país ainda possui um grande número de analfabetos, que precisam ser "recuperados" para que possam ocupar melhores postos de trabalho.

Os Parâmetros Curriculares Nacionais - PCNs e o Fundo de Fortalecimento da Escola FUNDESCOLA também carregam traços de políticas neoliberais, uma vez que, os PCNs que contêm as diretrizes curriculares que regem a educação brasileira são frutos de recomendações do Banco quanto à necessidade de reformas curriculares, desta maneira, eles de certa forma uniformizaram aquilo que deve ser trabalhado nas escolas. Já o FUNDESCOLA está a serviço da melhora setorial da educação, o que pode ser comprovado pelas ações por ele implementadas (BRASIL, 2006): planejamento estratégico das secretarias - PES; sistema de apoio à elaboração do plano de carreira do magistério público; sistema integrado de informações gerenciais - SIIG; plano de desenvolvimento da escola - PDE; projeto de melhoria da escola - PME, Programa Escola Ativa; programa de gestão da aprendizagem escolar - Gestar; programa de apoio à leitura e à escrita Praler; programa de melhoria do rendimento escolar; microplanejamento; espaço educativo; padrões mínimos de funcionamento das escolas - PMFE; levantamento da situação escolar - LSE; projeto de adequação do prédio escolar - Pape; mobiliário e equipamento escolar.

As ações desenvolvidas pelo FUNDESCOLA personificam as recomendações do Banco Mundial na educação brasileira à medida que transfere características empresariais para as escolas, percebemos que a educação e suas dificuldades são tratadas de modo setorizado, como a produção de uma indústria.

Por conseguinte, o que se tem visto na educação brasileira é a busca da redução de custos e a otimização dos resultados, que se traduzem na melhora de indicadores em avaliações externas como 


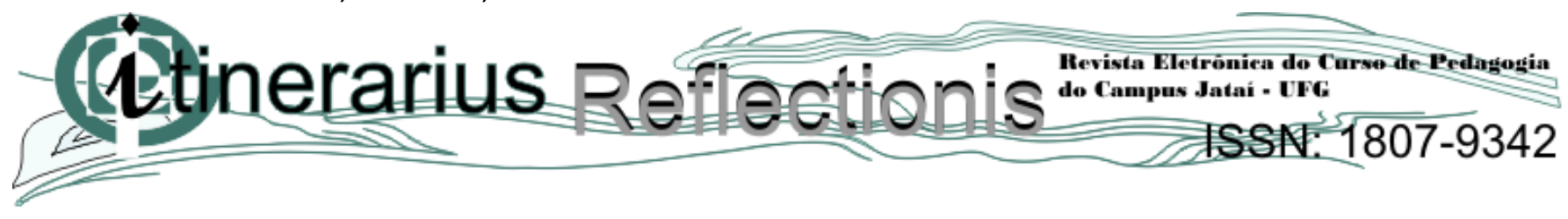

a Prova Brasil, o Sistema de Avaliação de Rendimento Escolar do Estado de São Paulo (Saresp), o Programa Internacional de Avaliação de Alunos (Pisa) e o Exame Nacional do Ensino Médio (ENEM), além da redução dos índices de analfabetismo e acesso à escola.

Pereira (2007, p. 18) endossa estas considerações ao afirmar que as análises do Banco Mundial convergem com o olhar do governo brasileiro, visto que, critérios econômicos como a eficiência e custo são uma constante nos projetos educacionais nacionais, o que desconsidera o processo educacional que forma o aluno, que deveria pensá-lo em sua totalidade e não como mero produto do processo educativo.

Em busca de conclusões percebemos que as condições precárias e as dificuldades de acesso aos bens públicos como saúde, seguridade social, habitação e educação acabam alargando a desigualdade social no Brasil, bem como a abertura indiscriminada do mercado brasileiro ao capital estrangeiro, traduzido na vinda de multinacionais para o país e privatizações em massa, reflexos claros das políticas neoliberais aqui desenvolvidas, sendo o veículo mais utilizado para sua disseminação, o Banco Mundial.

Este por sua vez, tem financiado políticas compensatórias de educação, que mais do que dar condições aos indivíduos de acesso aos bens culturais, têm tentado servir de medida de alívio da pobreza. Seguindo as recomendações do Banco Mundial, em busca de novos créditos, o governo brasileiro tem empreendido uma educação mínima, de baixo custo, que se reduz à obrigatoriedade do Ensino Fundamental, e voltada para a melhora de índices em avaliações externas e diminuição do analfabetismo, ou seja, a educação em nosso país está longe de ser instrumento de mediação entre os indivíduos, as práticas sociais e os conhecimentos historicamente produzidos pela humanidade. Ela está a serviço de políticas de favorecimento liberal, fornecendo aos trabalhadores brasileiros apenas aquilo que necessitam para integrar o mercado de trabalho capitalista.

\section{REFERÊNCIAS BIBLIOGRÁFICAS}

ANDERSON, Perry. Balanço do Neoliberalismo. In: GENTILI, Pablo; SADER, Emir (Org.). Pósneoliberalismo: as políticas sociais e o estado democrático. $3^{\text {a }}$ ed. Rio de Janeiro: Paz e Terra,1996, p. $9-23$

BÓRON, Atilio. A sociedade civil após o dilúvio neoliberal. In: GENTILI, Pablo; SADER, Emir (Org.). Pós- neoliberalismo: as políticas sociais e o estado democrático. 3. ed. Rio de Janeiro: Paz e Terra, 1996a. p. 63-118. 


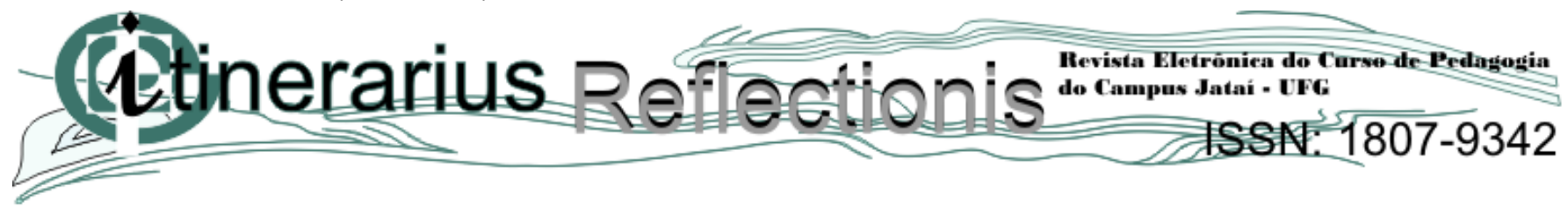

BÓRON, Atilio. A trama do Neoliberalismo: Mercado, crise e exclusão social. In: GENTILI, Pablo; SADER, Emir (Org.). Pós- neoliberalismo: as políticas sociais e o estado democrático. 3. ed. Rio de Janeiro: Paz e Terra, 1996b. p. 139- 180.

BRASIL. Comissão de Educação e Cultura. Projeto de lei do plano nacional de educação (PNE 2011- 2020). Brasília, 2011. 105 p. Disponível em: <https://docs.google.com/viewer?a=v\&q=cache:ww65LVtMxy4J:bd.camara.gov.br/bd/bitstream/ha ndle/bdcamara/5826/projeto_pne_2011_2020.pdf?sequence\%3D1+Lei+(PL)+n\%C2\%BA+8.035,+ $\mathrm{de}+2010 \& \mathrm{hl}=\mathrm{pt}-$

BR\&gl=br\&pid=bl\&srcid=ADGEESgi_jy9ouMZu5L2UHLu8lqmeIRbpJ37_gDOj5Xdp0ebgu2RrQ eZqcGxc_kYur3hhArS4p-

mh9YNVDij0brqlVxt2GnTAhz71Cp3zXWxPxc6_mMKTEwO3WYubtG444OaxQ5FG1AN\&sig= AHIEtbQQBhURz1O2UatR1sYNO1VMuYHUSQ> Acesso em: 22 mar. 2013.

BRASIL. Ministério da Educação e Cultura. Lei de diretrizes e bases da educação nacional. Brasília, $1996 . \quad$ Disponível em: <http://portal.mec.gov.br/seed/arquivos/pdf/tvescola/leis/lein9394.pdf> Acesso em: 05 maio 2012.

DELORS, Jacques (Org.). Educação: um tesouro a descobrir. Tradução: José Carlos Eufrázio. São Paulo: Cortez, 1998. 288p. Disponível em: < http://ftp.infoeuropa.eurocid.pt/database/000046001000047000/000046258.pdf> Acesso em: 22 mar. 2013.

FONSECA, Marília. O financiamento do Banco Mundial à educação brasileira: vinte anos de cooperação internacional. In: TOMMASI, Lívia de; WARDE, Mirian Jorge; HADDAD, Sérgio (orgs.). $O$ banco mundial e as políticas educacionais. São Paulo: Cortez, 2007. p. 229- 251.

MOLINA, Mônica Castagna. Políticas públicas. In: CALDART, Roseli Salete(Org.) et. al. Dicionário de Educação do Campo. Rio de Janeiro: Escola Politécnica de Saúde Joaquim Venâncio; São Paulo: Expressão Popular, 2012. p. 587- 596.

OLIVEIRA, Francisco de. Neoliberalismo à brasileira. In: GENTILI, Pablo; SADER, Emir (Org.). Pós- neoliberalismo: as políticas sociais e o estado democrático. $3^{\mathrm{a}}$ ed. Rio de Janeiro: Paz e Terra,1996. p. 24-28.

PEREIRA, Sandra Márcia Campos. Projeto Nordeste de educação básica e o FUNDESCOLA: uma análise do discurso governamental e do Banco Mundial sobre a qualidade do ensino. 2007. 149p. Tese (Doutorado em Educação). Faculdade de Ciências e Letras da Universidade Estadual Paulista, Araraquara, SP. Disponível em: <http://www.athena.biblioteca.unesp.br/exlibris/bd/bar/33004030079P2/2007/pereira_smc_dr_arafc 1.pdf> Acesso em: 23 abr. 2012.

SANTOS, Catarina de Almeida et. al. Avaliação de desempenho docente nas Redes estaduais de educação básica no Brasil. In: congresso ibero americano de política e administração da educação: gestão pedagógica e política educacional desafios para a melhoria da formação e profissionalização dos educadores. 3, 2012, Zaragoza, Espanha. 16p. Disponível em: <http://www.anpae.org.br/iberoamericano2012/Trabalhos/CatarinadeAlmeidaSantos_res_int_GT2. pdf> Acesso em: 12 de dezembro de 2012. 


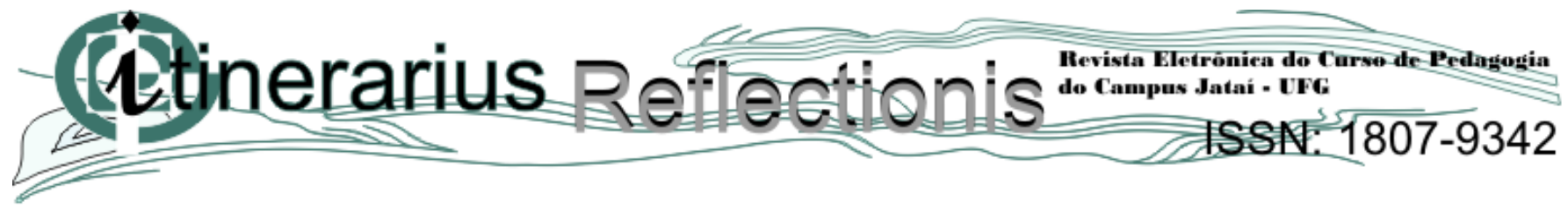

SAVIANI, Dermeval. Educação: do senso comum à consciência filosófica. 13. ed. Campinas, SP: Autores Associados, 2000b. 247p. (Coleção Educação Contemporânea).

SILVA, Maria Abadia da. Do projeto político do banco mundial ao projeto político- pedagógico da escola pública brasileira. Cadernos Cedes, Campinas, SP, v.23, n. 61, p. 283- 301, dez. 2003. Disponível em: <http://www.cedes.unicamp.br> Acesso em: 20 dez. 2011.

SOARES, Maria Clara Couto. Banco mundial: políticas e reformas. In: TOMMASI, Lívia de; WARDE, Mirian Jorge; HADDAD, Sérgio (Org.). O Banco Mundial e as políticas educacionais. São Paulo: Cortez, 2007. p. 229- 251.

THERBORN, Göran. A trama do Neoliberalismo: Mercado, crise e exclusão social. In: GENTILI, Pablo; SADER, Emir (Org.). Pós- neoliberalismo: as políticas sociais e o estado democrático. 3. ed. Rio de Janeiro: Paz e Terra, 1996. p. 139- 180. 
Primeiro semestre 2014, volume 1, número 16.

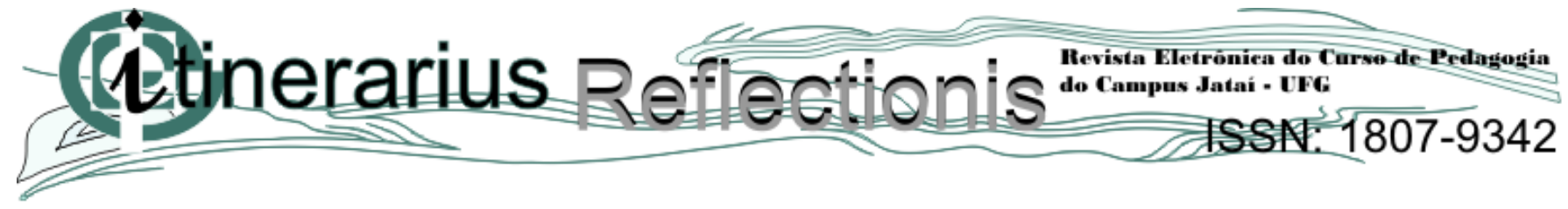

